\title{
Cytokeratin 16 Measurement
}

National Cancer Institute

\section{Source}

National Cancer Institute. Cytokeratin 16 Measurement. NCI Thesaurus. Code C127763.

The determination of the amount of cytokeratin 16 present in a sample. 